\title{
OBSERVACIONES A JAVIER DE LUCAS
}

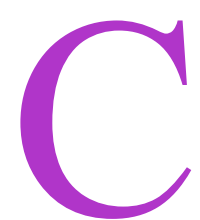

reo que la primera observación sobre la carencia de un planteamiento económico en materia de teoría de la representación política es justa y certera. Releyendo el trabajo constato que mi exposición, entre otros muchos defectos y carencias que generosamente elude mi amigo y compañero Javier de Lucas, adolece de un formalismo conceptual puesto que da por supuestas unas condiciones económicas homogéneas que sólo existen en el ámbito formal, con el riesgo evidente de legitimar, mediante la teoría de la representación, un modelo económico que permanece oculto y subyace a la democracia política. Las alusiones que se realizan en el texto a la división social del trabajo o al mercado político sobre las que se construye la teoría de la representación, corren el riesgo de quedar reducidas a meras declaraciones retóricas, ya que no se profundiza en sus contenidos y consecuencias. Creo además que esta es una carencia importante en la formación e investigación de la filosofía del derecho en España que venimos arrastrando más tiempo del que sería deseable, pese a las observaciones y llamadas de atención que al respecto formula E. Díaz sobre la necesidad de conectar y analizar las repercusiones que la democracia económica exige de la democracia política en el marco conceptual del Estado social y democrático de derecho. En el mismo sentido, cabría subrayar las aportaciones de Peces-Barba, en la línea de la fundamentación de un socialismo democrático; de Atienza, Capella y Laporta sobre el análisis del soporte económico de los derechos humanos; los trabajos de María José Añón sobre teoría de las necesidades en relación con los derechos humanos y los muy recientes análisis de Calsamiglia, Garzón Valdés, Ballesteros y De Lucas al respecto, todos ellos coincidentes en subrayar la carencia de un análisis económico del derecho, cuando menos con la misma intensidad con la que se 
analizan otros elementos y que implica en el mejor de los casos una formalización conceptual. Todo ello sin olvidar la denuncia, y consiguiente superación del formalismo en los métodos y contenidos de la enseñanza del Derecho que formuló la comunidad de filósofos del derecho españoles en las jornadas del año 82, en las que cabría destacar, en este sentido, las aportaciones de Capella, Ballesteros y Javier de Lucas. No me queda, pues, sino reconocer y aceptar dicha objeción.

Discreparía, en cambio, de la segunda observación que realiza Javier de Lucas y que se refiere a la no necesaria conexión, desde su punto de vista, entre el tema del sujeto de la representación y el objeto de la representación con el fundamento de la obligación política. Es verdad que, como mantiene también F. Laporta siguiendo a Pateman, son dos temas conceptualmente separados, aunque no por ello exentos en mi opinión de una estrecha relación. Son efectivamente dos cosas distintas la cuestión de quién gobierna y el problema de cómo se gobierna. Así, por ejemplo, también lo considera Bobbio, que en el análisis de la tradicional tipología de las formas de gobierno distingue un criterio cuantitativo que afecta a quien gobierna, del criterio cualitativo que permite valorar cómo se gobierna y distinguir, en consecuencia, entre formas buenas o perversas de ejercer el gobierno. Pero no es menos cierto, creo yo, que la pregunta por el cómo se gobierna no es una cuestión autónoma, sino dependiente de la cuestión referente al qué se gobierna, o al qué se manda. Y en este punto parece que sí hay cierta vinculación entre el sujeto de la representación, es decir, el quién representa y el objeto de la representación, esto es el qué se representa, puesto que una y otra están, desde mi punto de vista, sentando las bases y fijando los límites de la representación, de un lado, y de la obediencia al derecho, de otra. En otro caso, carecería de sentido el mecanismo de control y responsabilidad de los representantes por medio de los partidos o de los electores. En apoyo de esta tesis se podría argumentar el análisis que de la norma básica de nuestra Constitución realizan los profs. Peces-Barba y Laporta, por cuanto en el art. 1.1. de nuestro texto fundamental se encuentra la respuesta al qué se manda (los valores superiores) e, inmediatamente, en el párrafo siguiente, art. 1.2., encontramos la respuesta al quién manda (el pueblo español en quien reside la soberanía nacional, del que emanan los poderes del Estado). Sin esta estrecha conexión creo que se desvirtuaría la fundamentación de la obediencia al derecho o de la obligación política en base a un mandato autónomo que los ciudadanos se formulan e imponen sobre sí mismos y sobre todos y cada uno de los demás ciudadanos 
carecería de sentido, en consecuencia, la idea de la obligación moral de obediencia al derecho que en ese caso se impondría, sólo y exclusivamente, por la fuerza. 